\title{
Running Into Injury Time: Distance Running and Temporality
}

\author{
Jacquelyn Allen Collinson \\ University of Gloucestershire
}

Despite a growing body of research on the sociology of time and, analogously, on the sociology of sport, to date there has been relatively little sports literature that takes time as the focus of the analysis. Given the centrality of time as a feature of most sports, this would seem a curious lacuna. The primary aims of this article are to contribute new perspectives on the subjective experience of sporting injury and to analyze some of the temporal dimensions of sporting "injury time" and subsequent rehabilitation. The article is based on data derived from a 2-year autoethnographic research project on 2 middle/long-distance runners, and concludes with some indicative comments regarding the need for sports physiotherapists and other health-care practitioners to take into account the subjective temporal dimension of injury and rehabilitative processes.

En dépit d'un nombre croissant d'études en sociologie du temps et, de manière analogue, en sociologie du sport, il existe jusqu'à maintenant peu de recherches sportives centrées sur le temps. Étant donné la centralité du temps dans la plupart des sports, cette lacune est surprenante. Le but principal de cet article est d'apporter des perspectives nouvelles sur l'expérience subjective de la blessure sportive et d'analyser les dimensions temporelles du «temps de la blessure» et de la réadaptation subséquente. L'article est fondé sur des données dérivées d'une recherche auto-ethnographique de 2 ans sur 2 coureurs de longue distance. L'article se termine par des commentaires sur la nécessité, pour les physiothérapeutes sportifs et autres professionnels de la santé, de prendre en compte la dimension temporelle subjective de la blessure et des processus de réadaptation.

As indicated by a recent review of the research literature (Wiese-Bjornstal, Smith, Shaffer, \& Morrey, 1998), there is a developing body of psychological and sociological literature on sport injury. From sociological and anthropological perspectives, researchers have examined various factors influencing response to injury including inter alia socialization processes (Curry, 1993; Curry \& Strauss, 1994; Walk, 1997), the cultures surrounding specific sports (Frey, 1991; Howe, 2001; Krane, Greenleaf, \& Snow, 1997; Shaffer, 1996), the influence of social networks (Nixon, 1992), gender (Messner, 1992; Young \& White, 1995; Young, White, \& McTeer, 1994) and identity (Sparkes, 1996). Strangely, however, relatively little of this material devotes much analytic attention directly to the phenomenon of time as a feature of the sporting injury process. One can find some mention in the psychological literature, in terms of mood measurement of athletes during injury time (Wiese-Bjornstal et al., 1998, p. 52), whereas other research charts

The author is with the Leisure \& Sport Research Unit at the University of Gloucestershire, Gloucester, GL2 9HW, UK. 
individual athletes' particular history of injury (Curry, 1993; Sparkes, 1998). In the sociological and anthropological literature on sports and physical activity, there are some interesting references to time in, for example, Sands' (1995) ethnography of sprinters, Smith's (2002) work on the temporal characteristics of the social world of running, Wulff's (1998) anthropological work on ballet dancers, the notion that time in sport is not contiguous with "normal" time (Segrave, 2000), and the nature and role of time and space in sport in general (Eichberg, 1998; Shore, 1994). For the most part, however, as has been noted, "In a nutshell, analytical problems of space and time are more pretexts to sociological studies than really their object" (Métoudi, 1994, p. 370).

At first consideration, this appears somewhat curious given the centrality of, indeed often the fixation with, time in most sports, and what Eichberg (1998, p. 153) has termed "the hegemonic race-and-stop-watch model." Phrases such as time out, extra time, injury time, sin-bin time, and so on, testify to the importance of certain conceptions of time within sport. Additionally, injury time, in its broader sense of the period during which sportswomen and sportsmen are unable to pursue their activity due to injury (or are unable to participate fully), has a significant negative impact on the individual, on a range of levels, including the economic, social, and psychological. This is in addition to any potential long-term health consequences resulting from the physical injury. Yet on reflection, this relative absence of research on sport time or, more specifically, on injury time, is perhaps less surprising for, as Adam (2000) has noted, there is still a propensity for social time to be unproblematized and treated by many researchers as a neutral medium within which events simply take place. As a consequence, there is much research still to be done on the subjective experience of time within sports and its social construction in general (Yakura, 2001).

As various writers have emphasized, the social construction of time and its management varies between individuals, groups, and organizations (Bluedorn \& Denhart, 1988), being differentiated into a "multiplicity of 'loci' of sociotemporal orders" (Zerubavel, 1979, p. 106). There are some interesting empirical accounts of the social construction of work time in various occupational milieus and groups, ranging from Roy's (1959-60) classic ethnographic study of factory work, over graduate accountants (Coffey, 1994), to information technology consultancy (Yakura, 2001) to name but a few. Given such variety, the experience, construction, and management of injury time by professional athletes is likely to differ markedly from that of occasional or recreational participants in sport. Further, whilst time obviously plays an important role in team sports such as soccer, its importance in events such as running, where the raceand-stop watch model (Eichberg, 1998) prevails, is absolutely crucial: time, individual performance, and identity are fundamentally linked in this context. As Smith (2002) has noted, "Runners learn to attend to time as finely tuned markers of running achievement, as careers with stages and turning points, and as cyclical calendars" (p. 343).

The aim of this article is to examine the sociotemporal dimension of sporting injury, focusing on the injury and rehabilitation experiences of 2 distance runners. For the purposes of this article, four categories of time will be portrayed and examined: linear, cyclical, inner, and biographical. It should be noted, however, that these categories are not, of course, exhaustive and do not actually constitute discrete categories, but for analytic purposes it is useful to portray them separately. 
In addition to examining the role of time, the article seeks to contribute new perspectives to the developing literature on sporting injury, in three principal ways. First, much of the cited research on sports injury has used elite athletes as subjects or participants (Brock \& Kleiber, 1994; Sparkes, 1996; Young \& White, 1995). In contrast, the participants in this study, the female author and her male training partner, are of amateur "club" standard and therefore perhaps more typical of the mass of individuals who commit themselves to the pursuit of distance running and, consequently, have to contend with resultant injury time. Second, in contrast to much of the research, which focuses on athletes who are unable to attain their preinjured sporting status (Brock \& Kleiber; Sparkes, 1996, 1998; Young \& White, 1995), this study charts the successful temporal transition from the injured sporting body to the fully rehabilitated state. Third, a good deal of recent literature is based on the interviewing of injured athletes (Brock \& Kleiber, 1994; Sparkes, 1998) or the recounting of the researchers' own experiences of being injured at sport (Sparkes, 1996, 1999; Sparkes \& Silvennoinen, 1999). Both of these latter approaches rely largely on the recollection of events after their occurrence. In contrast, this research is based on data collected in "real time"- that is, during the actual process of rehabilitation.

\section{Biographical Baggage}

In order to contextualize the events to be described, it is necessary to render visible some accountable knowledge (Stanley, 1992) in terms of the athletic biographies of the author and her training partner. Collectively, the participants have a background of distance running that ranges from 5-mile races to marathons, requiring considerable self-instigated and self-imposed discipline (Foucault, 1979) and a time commitment of training 6 or 7 days a week, on occasion twice daily, for 17 years and 36 years, respectively. Moreover, we have been training together on a regular basis for the past 16 years. Now categorized as "veteran" runners, our involvement in the activity mirrors Stebbins' (1982) concept of serious leisure, which requires considerable personal effort, knowledge, and training, but also produces benefits in terms of physiology and social psychology, as we identify with being distance runners, and interact with others who display a similar level of commitment to the activity (Robbins \& Joseph, 1980).

At the time of the specific, traumatic injuries central to this account, both participants were training 6 days a week, for at least an hour a day, in the evening after work. On different days during the same windswept November week, we both suffered knee injuries, occasioned primarily by having to train in the winter dark on a local park strewn with branches and other assorted debris following several days of high winds. On the Tuesday, I stumbled into a branch, twisting my right knee forcibly, and stubbornly half ran, half limped through the remaining mileage. On the Friday, my partner slipped badly on a mud patch, wrenching his left knee, and was forced to shuffle his way tentatively home, swearing profusely. On that evening, we both sat in a state of shock, contemplating our injured knees, packed with ice, telling ourselves more in hope than prescience: "It will be all right". We instructed each other firmly to "do the right thing," "be sensible"; so we lowered the intensity of the training, consumed carefully selected anti-inflammatory tablets, and for the next month staggered and winced our way through the usual training mileage. For us that reduction in training constituted 
being "sensible." We still needed to "put in the miles" in order to feel better after the stresses of the working day, to sustain the fitness levels and above all else because this is what we did as athletes.

A few days following the onset of the injuries, it became apparent that they did not constitute the usual minor niggles that plague the habitual runner. At that point we arrived at a collective decision systematically to document our responses to these injuries, our principal motive being to achieve something positive from a highly negative experience. In this sense, it was one of those unhappy "accidents of current biography" that provided access, both physical and psychological, to the research setting (Lofland \& Lofland, 1995, p. 11) and stimulated the joint study. Had only one of us encountered traumatic injury at that point, it is debatable whether we would have decided to undertake the research.

The gender dimensions of the injury experience have been documented in relation to various sporting activities, mainly at elite level (see, e.g., Charlesworth \& Young, 2003; Young \& White, 1995; Young et al., 1994). Although there were undoubtedly differences in our experiences of, and responses to, the occurrence of the knee injuries and the subsequent rehabilitation process, careful analysis of the data did not suggest that gender was a significant variable in this case. The reasons for this are interesting to unravel. It has been suggested that female athletes adopt a so-called masculinist model of sports participation which valorizes a "no pain, no gain" approach similar to those of their male counterparts (Charlesworth \& Young, 2003). Although running is not usually constructed as a high-injury or physically dangerous sport, pain and injury are nevertheless routine, endemic, and normalized features within the distance-running subculture. As Young and White (1995, p. 51) found in their research on elite female athletes, if there is a difference between the way in which female and male athletes appear to understand pain and injury, it is only a matter of degree.

For both women and men, the very act of distance running is intimately connected with endurance. Tolerating fatigue and pain constitute an integral part of the everyday routine of distance running. Training can indeed be onerous "work" (Smith, 2002, p. 358); commensurate with the bodily conditioning required by the activity, there occurs a conditioning of the mind, as it learns to endure. As Crossley (1995, p. 47) has noted, the mind being inseparable from the body, they remain "reversible aspects of the same fabric"; hence, a particular kind of stoicism develops as one comes to accept physical suffering and injury. Our running selves (in terms of body and mind) were therefore habituated to enduring and persevering, and our self-images, including gendered self-images, reflected this. In this context, in common with Granskog (2003, p. 48), my definition of self has three critical components, in my own case: being a woman, a distance runner, and a feminist sociologist. For my part, combining the former two components has to-date proved empowering rather than problematic, and stoicism and endurance are certainly not constructed by most female runners of my acquaintance as "masculinist" qualities.

\section{Documenting the Data}

The approach adopted in this article is autoethnographic (Okley \& Callaway, 1992; Reed-Danahay, 1997; Sparkes, 2000). As the literature indicates, however, the term autoethnography has very different usages for those who employ it. Whilst some researchers' primary concern is the autobiographical (Deck, 1990), 
involving the portrayal of an individual life, in contrast, for other autoethnographers the emphasis is essentially ethnographic (Strathern, 1987). The narratives of autoethnographers are of particular ethnographic interest, being revelatory about the writer's membership of social groups and categories, and immersion in particular social processes. In relation to this particular project, the ethnographic process involved combining field notes with "head notes" (Sanjek, 1990). The self and the ethnographic field were symbiotic and, in effect, this combination constitutes the pivot of the analysis (Coffey, 1999). The individual and collective subjectivities of the researchers are integral parts of the ethnographic field, and the link between the two is forged by the writing. The use of the present tense, first person, and first person plural is therefore designed to convey an immediacy, together with the personal nature of the account (Sparkes, 2000). As Greenhalgh (2001, p. 55) has noted, there is a degree of risk involved in this genre of "vulnerable writing," particularly when it focuses on the emotion and pain experienced by the writer. Writing in such a personal and emotional style leaves the writer vulnerable to charges of being "irrational, particularistic, private, and subjective, rather than reasonable, universal, public, and objective" (Greenhalgh, p. 55). However, as Denison and Rinehart (2000) have recently advocated, there is a need to develop innovative and more evocative ways of writing sociological accounts that depict sporting experience. A primary aim of the present research project was to construct an account that was personal, evocative, and highly reflexive but also aimed at giving analytical purchase to the autobiographical so as adequately and evocatively to portray the ethnographic field.

The decision to record our engagement with the knee injuries presented no particular difficulty in terms of actual documentation, because keeping training logs is a common practice among athletes. Usually these logs document the kind of training in place at any particular time, and include details of distances, timings, terrain type, weather conditions, and so on. The discipline of recording daily training was therefore already well established, but instead of training logs we constructed injury-rehabilitation logs to record individual and collective engagement with the injured state, and the subsequent attempts to regain sufficient fitness to run again.

Each participant constructed a personal log, and a third collective log synthesized the salient, emergent themes, together with any differences in our individual adaptation to, and management of, the injured state. The recording of our experiences was done via notebooks and micro-tape recorders, which accompanied us during the working day and also during all attempts at rehabilitation. Tape recordings were transcribed as soon as practicable afterwards (usually in lunch hours and at weekends). Creating the joint log, within which analytical themes and concepts were generated, was undertaken via a process somewhat akin to the constant comparative method (Glaser \& Strauss, 1967), although to a less formalized degree. So, for example, if one participant had documented a particular narrative theme, we would search the other's log for a similar theme. We would then interrogate each other as to the precise composition of that theme, and its boundaries and connections to other themes previously generated. Thematic or conceptual differences between the accounts were identified and, wherever possible and desirable, reconciled in terms of definition. Where no analytical reconciliation proved achievable, the difference was accepted and recorded as such. Subsequently, we explored 
the reasons for the divergence and the impact, if any, on the process of injury management. Both participants sought to act as the "primary recipient" (Ochs \& Capps, 1996) of the other's data, providing regular feedback and critique. The current article is a product of this particular method, and the data collected over a 2-year period are extracted from our individual and joint field notes. In both the field notes and certain sections of the text, attempts have been made to write in a personal style intended to evoke the climate of emotion that pervaded at the time. Quotations from field notes are given verbatim, in order better to convey the immediacy of the feelings and mood. In the following account, as noted, four temporal dimensions of the injury and rehabilitation process are portrayed separately for analytical purposes although, in practice, they overlap and interrelate. The first of these temporal forms, linear time, will now be considered.

\section{Linear Time}

The years 1997-1999 brought bad times indeed: out of running, out of racing, struggling to return to previous fitness levels. The problem was that time did not of course stop; it ran on, ran inexorably away ... minutes, days, months, years, sometimes measured down to every parasecond. Time seemed ingrained in us: the relentless tick of clock, calendar, or linear time, time based on standardized, invariable units (Adam, 1990, p. 117), measuring our loss, in that particular way which has become pervasive, near hegemonic, in industrialized societies since the industrial revolution (Thompson, 1967; Thrift, 1990; Yakura, 2001; Zerubavel, 1981). Time marked us, and we marked ourselves with its passage. It had etched itself on us, year after year, as our faces became progressively more gaunt, and our bodies lean as a result of the habitual body discipline practices (Foucault, 1979) demanded by middle- and long-distance running. We gauged our progress by time and optimistically, uncritically, had arranged our future by it, assuming that training in a certain manner for a certain period of time would result in a certain level of performance for $10 \mathrm{~K}$, for 10 miles, for the marathon. In that manner familiar to runners, we were our times (the times achieved in races over various distances), we located and identified ourselves and others by such times (Sands, 1995; Smith, 2002), and those times indicated, for example, our level of fitness, they were inscribed on our biographies, recited to ourselves and to other runners who invariably ask of each other: "What have you done for . . . ?"- that is, what is your best performance over a particular distance.

Unfortunately, during the injury period, we were forced to endure the kind of "time out" we never envisaged; we were deep into injury time and wanted desperately to return to normal running time. Running time had always been hard won for both of us, determinedly ring-fenced against competing occupational, familial, and domestic demands and responsibilities. Sixty minutes had become the daily minimum training time, constrained primarily by the demands of full-time work; more than 60 min was a bonus, less was often a source of intense frustration and discontent. During the injury time, we were intent on reclaiming that precious 60min allocation, and a decision reached early on in the process was that normal training time would be transformed into rehabilitation time. Over a 2-year period, therefore, the nature of "training" graduated from slow walking, via jogging, and then running short sections interspersed with walking, eventually to running at normal pace, continuously, for lengthier time spans. 
Linear time became the main marker of progress toward athletic fitness but, unfortunately, it also became the marker of periodic failure as the knees rebelled against the progressive increase of effort, and rehabilitative efforts consequently had to be scaled down. Linear time and biography were then inextricably linked. When rehabilitative progress was achieved, many of the temporal markers used to chart that progress were intimately connected to our running pasts. Thus, when we managed 1 full minute of constant jogging, that time period had significant resonance for my partner because track quarters had been covered in that time decades before. Likewise, 7 min of continuous running was a somewhat poignant reminder of an early-career $10 \mathrm{~K}$ road race, run at 7 min per mile. The celebrated landmark of $60 \mathrm{~min}$ of running not only announced our return from injury, but also held significance because we had always used that amount of time as a marker of aerobic capacity: The "Big 60" represented a base of distance running training, off which different kinds of racing could be undertaken. Subjectively, the return to a 60-min running session indicated a resurrection of the status of "real runner." Each of these positive temporal markers connected intimately with our biographies, not surprisingly perhaps, given the identity salience (Stryker, 1987) of distance running in our lives. Counterposed against these positive indicators, however, were the inevitable setbacks in the rehabilitative program, when the links between the time(s) we had failed to achieve and the running past were particularly negative. For example,

We are on the park trying to jog 30-second intervals, with a minute's walk between each one, for a total of five minutes. ... It's cold and wet and we hold each other's coat as each of us does a session. We are on the flattest bit of the park, so we minimize holes and divots; we want the ground as smooth as possible to reduce stress on the knees. We trot up and down the white lines marked out for the primary (elementary) school sports day, egg and spoon races etc. What we are doing is farcically slow, but despite this our knees become painful and we quit the session at 5 . Coats back on, with the clouds as low as our mood. I look at the markings and comment that I ran better times on this kind of course when I was 8 or 9 than I have today. (Individual $\log 1)$

Linear time consequently marked the passage of injury time generally and was used to measure and make sense of our progress, and also periodic failure. These cycles of progress and regression generated another kind of time: cyclical time.

\section{Cyclical Time}

This particular conceptual approach developed out of the groundbreaking and influential work on social time of Sorokin and Merton (1937), which theorizes the relationship between the meaning of an event and its temporal setting, noting that "systems of time reckoning reflect the social activities of the group" (p. 620). In industrial societies in particular, it is posited that there exists a plurality of social times linked to particular groups and social classes (Gurvitch, 1964). From this perspective, time is experienced within social events, themselves subject to definition by social and organizational actors, hence their qualitative nature. As a consequence, time does not exist outside events (Clark, 1985). There is much imprecision 
to these qualitative temporal units; they resist quantification and tend to be highly local. So it becomes possible to speak of a plurality of times that are relative to particular members, located within particular groups, doing particular activities. The cyclical form of these events lies in their periodic recurrence, which may range over minute-long cycles - for example, in engineering shops or on production lines (Cavendish, 1982; Roy, 1959-60), the perimonthly cycle of menstruation, to the longer term- or semester-based cycles manifest within higher education institutions (Lawrence, 1994). Just as the wider society pulsates to its own general cultural rhythm, it is argued (see, e.g., Durkheim, 1976; Mauss, 1966), organizations, occupational groups, sporting and leisure groups, and so on, move to the rhythm of their particular, recurrent event times (Clark, 1985). The fundamentally cyclical structure of the temporal organization of the running world has been described by Smith (2002, p. 347). Two principal features of this temporal structure, which he highlights, are the cyclical racing pattern, and also the planned and scheduled character of training, whether athletes are training for competition or for general fitness.

In terms of the cyclical dimension of our rehabilitative journey, with hindsight, it is interesting to note the phrases and metaphors used to portray this journey. The field notes are replete with phrases such as the road back, the track back, the way back, and so on. These were employed in a manner seemingly presupposing a straightforward, progressive journey: we would simply set out on the path, seek and receive the appropriate medical treatment, follow the remedial program faithfully ... and at the end of the rehabilitation program would be fully recovered from the knee problems. Right from the journey's start, however, there was to be no smooth, linear progression. Although help was indeed sought from various UK health-care providers, including a general practitioner specializing in sports injuries, physiotherapists at a local sports injury clinic, an independent sports physiotherapist, an osteopath, and a consultant surgeon at a national center of excellence for knee injuries, we were obliged to abandon the medical pathway on the grounds of its inadequacy and prohibitive expense. The medical practitioners had all proffered different diagnoses, ranging from chondromalacia patellae, prepatellar bursitis, plica, osteoarthritis, to injuries of the tibial tubercle, the menisci, or the medial ligament, respectively. We each received a 10-week course of physiotherapy treatment, employing a range of modalities-in my case, mainly ultrasound and diathermy, intensive remedial exercises designed to strengthen primarily the vastus medialis, and the application of support taping. On completion of the course of treatment, however, there was no discernible improvement in the pain level or degree of mobility for either of us. Subsequently, we underwent expensive magnetic resonance imaging (MRI) scanning at a national center of excellence but were informed that the scans were "inconclusive" and that investigative knee operations would be required. (For further details, see Allen-Collinson \& Hockey, 2001.) Unable and unwilling to submit to expensive operations, in an act of individual and collective empowerment (Seymour, 1998), we consequently decided to take charge of our own athletic destinies.

After extensive reviews of the sports injury and self-help literature, both published (e.g., Grisogono, 1988, 1989) and Web-based, informal advice from other athletes, and collective experience of dealing with a range of previous running injuries over the years, we carefully devised our own remedial programs. These were based on progressive loading of the knee joint and very gradual increases in intensity and length of running duration, combined with daily strength- 
ening exercises. The reality of rehabilitation, however, rarely conforms to the neat, chronological progression characteristic of some of the sports literature, as the joint $\log$ testifies:

We are into it, struggling with it, every time we tried to drive forward it caught us, lassoed us, snared us, hooked us back into its injurious, painful jaws, and every time we failed to see it coming. The ritual process of dressing up warmly, even when the weather is mild: three layers over our knees, walking down to the park, and then trying to push those training flats a bit further out of the injury zone. Two weeks on: 5 minutes jogging, so let's try 8 now. Chancing it, risking it. A week on 8 and we are collectively smiling, humming, and then-it's ambush time! J's left knee swells up suddenly and returns to that old familiar throbbing rhythm. Great surges of vitriolic swear words cascade downwards to the knee, fuelled by disappointment, rage, impotency. (Joint Log)

The rehabilitative process involved a familiar sequence of allowing the injuries to heal to a point where they could tolerate a certain level and duration of physical activity, then maintaining this for a set period before the threshold was raised to the next level. However, perhaps predictably, this linear pattern was frequently disrupted during the 2 years by regular failures of the knee, which resulted in regression, sometimes substantial regression. This cyclical pattern is akin to what Clark (1985) has termed "event time". In contrast to clock-based time, conceptualized as linear and quantifiable, event time is essentially qualitative and cyclical in nature.

The field notes graphically illustrated the presence of an event-based cycle within the rehabilitative process. Although not as regular or predictable as, for instance, those within certain occupational milieux, the cycle occurred with sometimes dispiriting frequency, was rarely anticipated, at least initially, and had a highly capricious nature; the precise causal pattern of physical breakdown could rarely be accurately ascertained. Over the 2 years of rehabilitation, we found ourselves caught repeatedly in this cycle, although fortunately the time intervals between advance and retreat progressively became longer as the injuries slowly healed.

The period of rehabilitation was structured by the two forms of time portrayed above. These were intimately connected and interrelated: linear time provided the overall temporal framework but, within that overarching framework, event-based time operated, structuring the cycle of rehabilitation, which consisted of walking, jogging, running, and specific remedial exercises. As is indicated by the field notes, a third kind of temporality emerged as salient: inner time, or durée, "the present moment of the lived experience" (Schutz, 1932, pp. 45-52).

\section{Inner Time}

Melucci (1996, p. 18) has noted how inner time is linked to the individual's emotions, sensations, and perceptions. For, as Crossley (2001) has observed, when adopting a non-Cartesian position: "Human beings are neither mindful minds nor, strictly speaking, bodies, in this view, but rather mindful and embodied social agents" (p. 3). Interrogation of the data revealed that, as rehabilitative activity progressed, embodied time was experienced in two analytically distinct ways relating to the speed at which time appeared to pass and to a corporeal sense of timing. 


\section{Slowing, Speeding, and Steady Time}

First, perceptions of time and the consequences of these will be examined for, as Bergson (1910, pp. 36-37) long ago noted, the experience of time cannot be divorced from its effects. The field notes made clear that different experiences and perceptions of time emerged over the 2-year period of injury and rehabilitation. For instance, during the acute phase of injury, it became apparent that time seemed to elongate, to extend:

My left knee is screaming for attention, as if it's all of me. Cradling it in my hands as I sit on the ground, the vicious pain radiates upwards causing the quad muscles to go into spasm. All I can think of is a sort of mantra, which I recite repeatedly: "Hell, what have I done, what have I done?" over and over. I seem to be there for an eternity, on the ground holding my knee up away from the slippery mud patch that has caused such havoc. (Individual Log 1)

At the initial point of injury, each of us came to a juddering halt, in a state of shock, the pain stabbing the knee, jangling through the body, standing then sitting in fear, drenched with anxiety, asking the same question over and over: "Will I be able to run again?" Reading the accounts, the slowing of time at this phase emerges as a salient feature; we felt trapped in the negative event for an inordinate length of time. After the initial onset of injury, this temporal expansion recurred at various points in the recovery process when we seemed in danger of regression. Indeed, a degree of anxiety was always experienced whenever the training intensity was increased, however gradually and carefully.

In making rehabilitative progress, we managed to reestablish some kind of order in our athletic lives. For long periods, however, that order was extremely fragile. As Kleinman (1988) has noted: "Change, caprice and chaos, experienced in the body, challenge what order we are led to believe-need to believe-exists" (p. 55). This brittle order was particularly problematic because periodically, and apparently randomly, the knees would refuse to tolerate the increased duration of training. Acute pain would ensue, and we would find ourselves flung back down what we termed the "time tube," overwhelmed again by trepidation and fear that the reactivated pain was not after all mere temporary soreness but constituted a major breakdown of mechanical function, threatening recovery in toto. The timetube phenomenon therefore rekindled the same emotional deluge and oscillations (Rosenblum, 1990) as originally experienced at the point of injury. During these periods, time slowed and extended, and the moments of crisis seemed to drag on endlessly. The following example of temporal extension occurred in the second month of the injury process, at a point when we were still receiving woefully inadequate medical treatment:

Went into the physio's feeling positive and cheerful. Unfortunately, she, in her wisdom, decided to "test" my progress by making me do a squat. Heaven only knows, why did I listen to her?? I know better than to do that. Should have followed my own feelings. ... Didn't even attain the full squat position when I felt the knee suddenly give way, snap, break, grind - whatever. Horrible, shooting, stabbing, crunching, gritty pain. Shocked in to silence. I look around for something with which to pull myself up and out of the pain. I'm stuck for what seems forever. An age passes before J comes across the room to help me up. (Individual Log 2) 
In between these points of minor crisis, time normalized in the sense that its passage was not perceived to be excessively swift or slow and therefore roughly synchronized with linear or clock time. At this point in the recovery process, however, we felt angry, frustrated, and unfit, with the condition of our knees ranging over a spectrum of sensations from sore or aching, through stiff and grating, to intense pain on occasion. As we advanced, very slowly the worst of the symptoms diminished. Inevitably, during the 2-year period, there were setback points when the knees rebelled, suddenly returning to a state of instability, effusion, and stabbing pain. At these junctures, the time-warp phenomenon recurred, until the pain and the emotion subsided. Subsequently, the increasingly familiar cyclical process occurred as we managed to surmount the fear and disappointment of enforced regression in the remedial program, and time once again normalized.

In the final quarter of the 2-year recovery period, as the specter of breakdown receded, although fear was always lurking, it gradually became more distant with the passage of time, and particularly in the absence of any major episode of enforced time-tube travel. During the last couple of months, aerobic fitness developed to a state correlated in memory with serious running and ultimately potential racing. During this period, there were rare, but happy, instances when some sections of the normal rehabilitative run would recede from the forefront of consciousness. This happened both individually and, on one occasion, collectively. In these instances, time seemed somehow to close in on itself. This temporal constriction (Leder, 1990) was intimately connected with enjoying a training run of great ease, in the case of the extract below, during a much-needed week's holiday:

This morning started on the sea front, ran briefly down the Avenue de la Mer, and took a left into the pinewoods. It was cool and we were going out and back for 45 minutes. The going was great, flat, soft and with masses of fallen pine-needle cushioning. Very quiet with nobody around, just the sound of your own breathing. Could tell we were going well straight off. Most interesting thing about the session was I had no conscious recollection of a couple of long sections of the sentier [footpath] either during or after the event! One section has a surface which is particularly smooth and we'd previously marked it as a place ideal for speed-work. The other section that 'went missing' was where a single house is directly adjacent to the route and we always remarked on its typically French bright blue window shutters. No recollection of passing through either of those sections. (Individual Training Log 1)

Following such runs we experienced intense pleasure, primarily because decades of distance running experience indicated that, only when the running was going really well, when we were "on top of things," did such temporal shifts occur. These running sessions were supremely effortless and just seemed to flow (Csikszentmihalyi, 1975).

During the recovery process, our experiences and perceptions of time spanned the various dimensions of extending, contracting, and normal time (or slowing, speeding, and steady time). These conceptions of time appear to approximate the theoretical formulation of Flaherty (1999), who has used the terms protracted duration, temporal compression, and synchronicity, respectively, to illustrate the above 
continuum of temporal perception. Synchronicity applies to perceptions of time that equate roughly with the standard temporal units underpinning much of routine social interaction. Usefully, Flaherty (pp. 43-83) also outlines a number of factors that, according to his theory, are capable of producing protracted duration. The two most apposite to our account of injury and rehabilitation would be: "suffering and intense emotions" and, to a modest extent, "violence and danger." Whilst in no way wishing to exaggerate the degree of suffering or danger in relation to the knee injuries, the experience was initially intensely painful, with recurrences of a similar level of pain on subsequent occasions. The risk of being unable to run again was certainly experienced as dangerous, in relation to both physical and psychological well-being.

In the throes of these negative experiences, we became totally absorbed with the knees and the threat to their functioning; we were, in Goffman's (1972, p. 50 et seq.) terms, "flooded out" with intense emotions: alarm, anxiety, fear, dread, panic, to name but a few. In conjunction with focused concentration, the storm of emotions served perceptually to elongate time. In contrast, mirroring Flaherty's concept of temporal compression, time occasionally moved at high velocity. During the last few months of remedial work, the running incrementally became smoother, easier, and even enjoyable to the extent that, on occasion, we would forget ourselves and just flow. In our own terminology, we would "go on automatic". This state of being has been noted amongst groups as diverse as rock climbers (Csikszentmihalyi, 1975, pp. 43, 86) and commercial cooks (Fine, 1990, p. 109) in relation to tasks that, whilst challenging, are well within the required levels of skill or ability. Once our levels of running skill (aerobic fitness, endurance, muscular power, coordination, etc.) had reached the point where we could run with relative ease, occasionally the running time flew.

\section{Timing the Running Body}

Another way in which the embodied experience of time affected the injury and recovery process centered on the loss and subsequent regaining of a particular kind of timing. This Goodridge (1999) defines as "the act of determining or regulating the order of occurrence of an action or event, to achieve desired results" (p. 44). As she also notes (Goodridge, p. 45), timing is essential for skilled performance in social life generally but is particularly crucial to sporting success (cf. Lowe, 1977, p. 177). Running demands a particular kind of embodied timing, as a component of the runner's time habitus (Métoudi, 1994, p. 371), and the performance of distance running and racing requires a specific variant of this. Our acute sense of timing had been fractured by protracted injury time. For 10 months, we had been unable even to jog at a slow pace and, in that time, the grounded, embodied understanding of how to run had been lost.

For nonrunners, this loss or amnesia regarding how to run may seem a bizarre conceptualization, for running is socially constructed as a natural activity for most "able-bodied" people. However, in common with many such activities, running actually requires a complex series of actions, accomplished via a continuous rhythmical cycle. In a general sense, this rhythm constitutes the pattern of action, while simultaneously it also structures and creates its particular shape or order of movement. Timing involves the coordinated placing of various body parts in a certain direction, at a particular tempo, for a particular duration. The principal 
movers are clearly the legs, operating at a particular pace or cadence which, coordinated with the respiratory system, inter alia, produce forward movement. This simultaneously requires continual adjustment of footfall, as the demands of terrain are negotiated, and this is facilitated by a particular, learned way of seeing the terrain (see Goodwin, 1995). This in turn permits the precise bodily adjustments necessary for the chosen footfall and cadence. Such intricacies of timing had, however, been rendered highly problematic for us, as revealed in the following extract:

We have started to run, which, whilst anxiety provoking is also energizing because we are on the way back. Initially tried some tiny 10-metre trots with rests in between, but to our consternation are like babies! Like drunks we stagger all over the place. No coordination, legs out of kilter with arms, unused to the effort so breathing is ragged, legs do not seem to fit with the torso, and head feels wobbly and heavy. Even these baby trots tire us, compounding the problem. So much for our veteran runner status, this is a reality-shock because we now truly know we are absolute beginners once again. (Individual $\log 1)$

In the ensuing 14 months, we falteringly and haltingly relearned how to distance run. This required teaching ourselves how to coordinate the body again, how to fuse cognitive and physiological processes in order to construct something approximating a running rhythm. As fitness and confidence in the strength of the knees slowly increased, the sense of athletic timing gradually returned. Before the onset of injuries, the sense of timing had been highly developed and attuned. Both of us could, with a fair degree of accuracy, ascertain the actual pace of our running via a range of bodily indicators, such as respiratory rate, but also more nebulous corporeal sensations. Indeed, previously, this timing had been routinely articulated during training runs. Such timing constituted part of our body habitus (Bourdieu, 1990), habitual, embodied practices. Body habitus, Harvey and Sparks (1991) concisely summarize as "a system of implicit schemes (dispositions, appreciations) that govern one's relation to one's own body" (p. 173). One of these schema, our sense of timing, had been developed and refined by thousands of miles of running practice, of bodily labor (Wacquant, 1995, p. 67). As a result of prolonged injury time, this embodied timing had been forgotten. We had lost what Bourdieu (1998, p. 80) might have termed our "feel for the game" that previously had allowed us to run freely and to adopt the correct strategies when training and racing. Happily, eventually this sense of corporeal timing began to return towards the end of the 2 years of rehabilitation, as we relearned to associate and categorize various levels of bodily effort according to linear time:

Going well today, and for the first time I acted like a real runner again. I suddenly said to J: "This feels like $7 \mathrm{~s}$ " [7 min per mile], and he nodded agreement. A little further on in the session I realized what I had done and the import in terms of our return to the kind of runners we had been. We had not done that kind of automatic evaluation of pace for a very long time. Once finished, I checked on the watch and it was indeed approx the pace I had felt intuitively. That's a big marker for us-on the way back! (Individual $\log 2$ ) 
Leder (1990, pp. 30-32) has perceptively depicted the phenomenological processes that make up the learning of corporeal skills, the combination of specific movement and cognition, which are termed incorporation. Via the rehabilitative program, we achieved the reincorporation of our running skills. As Leder notes, "Incorporation thus has a temporal significance. The body masters a novel skill by incorporating its own corporeal history of hours and days spent in practice" ( $\mathrm{p}$. 32). In our case, it was not a novel skill, but an existing one that had been lost, temporarily at least.

\section{Biographical Time}

The linear, cyclical, and inner temporal forms so far examined were intimately connected to another temporal dimension, that of biographical time. Our individual and collective biographies were inscribed with running time, not only in terms of the significant portions of our lives devoted to training and racing but also because past biographical time was employed as a basis on which to construct the present and from which we aspired to move to a healthy running future.

This was partially accomplished via the formulation of narrative which, Richardson (1995) contends, "provides powerful access to this uniquely human experience of time" (p. 208). We selected and retrieved stories from the running past and articulated these to ourselves reflexively and also to each other, for these narratives constituted interactional achievements, with each person acting as coteller for the other (Ochs \& Capps, 1996, p. 31). As indicated above, many of these stories related to previous running successes and accomplishments. In reliving these moments during difficult times, they provided positive affirmation when morale was low. So, for example, we recalled marathons raced in the torpid heat of the summer; rain-drenched training runs on the storm-blasted, bleak beauty of the northern English fells and moors; the bitter, lactic-acid aftermath of exhausting hill repetitions. These tales of our "gloried" athletic selves (Adler \& Adler, 1989), tales of fortitude, commitment, and above all endurance, constituted the narrative work used to bolster fragile identities in the nadir of non-running time. Those very qualities, we assured ourselves, would propel us into a healthy running future.

Narratives of the more immediate, injured past also provided indicators of progress when, for example, contrasting the state of the injuries 3 months earlier at a point when climbing stairs was nigh on impossible, with the happier circumstances of being able to walk along a ridge of small hills. Narratives of the past were, however, sometimes problematic and rather poignant, particularly when juxtaposed with current faltering attempts to rehabilitate the knees. Failure to make even small advances often made woeful comparisons with earlier and more positive running and racing endeavors. More positively, however, we began to construct narratives which stressed that, when in rehabilitative mode, "small is big," in the sense that each tiny incremental step forward was of relative significance and should be viewed as a positive step on the path to eventual recovery. "Small is big" consequently became a routine, ritual utterance, a stock reminder at the beginning of each remedial session, and constituted a device that helped us concentrate on the "now," the immediate lived present. 
Further reinforcement of the need to focus on the remedial present arose from the periodic failures to progress, when training levels consequently had to be reduced. In the early days of rehabilitation, often we would optimistically map out the future: 2 weeks at 5 min of trotting, and then 10 min for 3 weeks - functional progression. By the summer, we estimated, we would be pulling on the racing shorts and handling $10 \mathrm{~K}$ without problem. Regrettably, the future periodically failed us; it failed to materialize in the way we had projected, only serving to intensify feelings of disappointment and rage. Subsequently, suitably chastened, we decided to narrow our horizons to something less adventurous. We refused to adopt the long-term perspective or even the medium-term. The future consequently became compressed to a week's timeframe; we "zeroed in" on the week's end-that was the far horizon. The objective was to get to Saturday intact, with the knees able to tolerate the target training time. Decisions in terms of training load were made in the here and now of each session, with the objective of arriving safely at day's end; and then maybe ... the week's end.

The way in which future time was conceptualized also underwent a marked shift in perspective that was fundamental to our relationship with the running present and past. Biographically we were inscribed with our previous competitive times, our running identities were anchored in them, and they were markers of considerable significance. As the 2 years came to a close, the meaning of those times began to diminish in importance to us. The knee injuries had seriously threatened our capacity to run in toto. Consequently, it was no longer a question of racing well or badly, of fast or slow training pace-it was a question of being able to run at all. The period of injury had resulted in a drastic reconfiguration of the meaning of running for both of us, as demonstrated by a field note:

A conversation that has cropped up a lot this week is about what running means for us now. I suspect we are having this kind of talk because we have just got back to where we were in running time [1 hr]. We both agree the most important thing about running now is just daily doing it, not whether we are doing it well or badly, not for preparing to race, not the racing, not the improved performances, but just doing it. Getting out there, putting the time in. All the rest is secondary now. If those things happen, they happen. Being without it for such a long time, when you get it back, the absence has sort of impressed the running essence on you. (Individual Log 1)

This shift in meaning subsequently changed perceptions of future running time. In a directly experiential way, we were well aware that serious injury really might finally put an end to running time. Being veteran runners, the 2 years' absence made us acutely aware that the amount of running time left to us was inexorably diminishing. The combination of these factors resulted in serious attempts to safeguard future running time by adopting various strategies aimed at injury avoidance. Revised training routines were drafted and are still operational today, geared to minimizing road and pavement running in favor of softer surfaces, in order to reduce impact and stress on the knee structures. In general, anything that places undue stress on the knees is avoided as far as practicable, including hill work and a whole gamut of strengthening exercises involving squats. Training schedules have had to be altered permanently. We invest in ludicrously expensive waterproof running gear to keep the knees as dry as possible in the rain. Via these practices, 
we fervently hope to be in for the "long run"- not in terms of miles, nor of speed, but in terms of years and, hopefully, decades.

\section{Conclusion}

\section{As Schutz and Luckmann (1973) indicate:}

The structure of life-worldly time is built up where the subjective time of the stream of consciousness (of inner duration) intersects with the rhythm of the body as "biological time" in general, and with the seasons as world time in general, or as calendar or "social time." (p. 47)

This article has sought to portray something of the temporal complexities experienced by 2 injured distance runners over a 2 -year period of injury and rehabilitation. First, linear or clock time provided the overarching temporal framework and the means by which failure or progress were gauged in terms of recovery to running fitness. Second, and simultaneously, cyclical or "event time" ordered the transitional period from injury toward recovery, which took the form of an oftrepeated cycle of progress and regression. Another form of temporality, embodied inner time, structured our perceptions and subjective experience of time. In addition, biographical time inexorably ticked away throughout the whole injury and remedial process, but also influenced the experiencing of it, as our athletic pasts and projected futures were constructed and contrasted with the emergent present (Luhmann, 1982; Mead, 1959). These forms of time are not of course comprehensive and, in portraying the various dimensions described above, one crucial temporal facet is perhaps missing: biological (Adam, 1990, p. 70), "knee time". For the knees had their own healing time, linked inevitably to the other forms of time analyzed above. Despite best efforts, we never fully understood the knees' own temporal timeframe and peculiar, capricious rhythms of healing and breakdown.

The different temporal dimensions did not, of course, operate in isolation but were interrelated (Adam, 1990, p. 45), interlocking, and mutually influencing. Clock time, for example, pervaded cyclical time, as it was used to measure remedial success or failure. Clock time also permeated biographical time, as the times of past performances (whether in training or racing) were used to construct the present and the projected future of rehabilitation and running. In a cognate fashion, the relearning of embodied timing within inner time was inextricably linked to both clock time and biographical time.

It is hoped that the above account gives some indication of the temporal complexity of athletic "injury time". Given the relatively limited literature, and the apparent underuse of anthropological and sociological research literature on time in relation to sport, there would appear to be fertile grounds for charting and analyzing the temporal dimensions of sporting activity in general and, more specifically, their impact on athletic identity construction and maintenance. In addition, as was clear from the autoethnographic research undertaken, our experience of the various temporal forms heavily influenced our responses to injury time and our motivation and morale during the rehabilitative process. The importance of the temporal, in the form of a phased, rehabilitative program, is acknowledged by many physiotherapists and other health practitioners and is well documented (see, e.g., Anderson \& Hall, 1995; Crust, 2003; Heil, 1993; Taylor \& Taylor, 1997), but 
further in-depth research is undoubtedly required in order to unveil in greater detail the impact and consequences of the subjective temporal dimension of sports, and also sports injury and the recovery process. The role and importance of the subjective experience of time should not be overlooked by physiotherapists, sports psychologists, counselors, and other health-care professionals involved in the rehabilitation of injured athletes and sportspeople in general.

\section{References}

Adam, B. (1990). Time and social theory. Cambridge: Polity Press.

Adam, B. (2000). The temporal gaze: The challenge for social theory in the context of GM Food. British Journal of Sociology, 5, 125-142.

Adler, P., \& Adler, P. (1989). The gloried self: The aggrandisement and the constriction of the self. Social Psychology Quarterly, 52, 299-310.

Allen-Collinson, J., \& Hockey, J. (2001). Runners' tales: Autoethnography, injury and narrative. Auto/Biography, IX, 95-106.

Anderson, M.K., \& Hall, S.J. (1995). Sports injury management. Media, PA: Williams \& Wilkins.

Bergson, H. (1910). Time and free will. London: George Allen \& Unwin.

Bluedorn, M., \& Denhart, R. (1988). Time and organizations. Journal of Management, 14, 299-320.

Bourdieu, P. (1990). The logic of practice (R. Nice, Trans.). Cambridge: Cambridge University Press.

Bourdieu, P. (1998). Practical reason. Cambridge: Polity Press.

Brock, S.C., \& Kleiber, D.A. (1994). Narrative in medicine: The stories of élite college athletes' career-ending injuries. Qualitative Health Research, 4, 411-430.

Cavendish, R. (1982). Women on the line. London: Routledge.

Charlesworth, H.L., \& Young, K. (2003). Female athletes and their motivations for playing with pain. Paper presented at the 2nd World Congress of Sociology of Sport: Sport and social order: Challenges for theory and practice, Cologne, Germany.

Clark, P.A. (1985). A review of the theories of time and structure for organizational sociology. In S.B. Bacharach \& S.M. Mitchell (Eds.), Research in the sociology of organizations. Greenwich, CT: JAI.

Coffey, A.J. (1994). "Timing is everything”: Graduate accountants, time and organizational commitment. Sociology, 28, 943-956.

Coffey, A.J. (1999). The ethnographic self: Fieldwork and the representation of identity. London: Sage.

DoffeyCrossley, N. (1995). Merleau-Ponty, the elusive body and carnal sociology. Body and Society, 1, 43-63.

Crossley, N. (2001). The social body: Habit, identity, and desire. London: Sage.

Crust, L. (2003). In the psychological adjustment to injury, what techniques work best in getting the athlete back to full activity? Sports Injury Bulletin, 27, 3-4.

Curry, T.J. (1993). A little pain never hurt anyone: Athletic career socialization and the normalization of sports injury. Symbolic Interaction, 16, 273-290.

Curry, T.J., \& Strauss, R.H. (1994). A little pain never hurt anybody: A photo essay on the normalization of sports injuries. Sociology of Sport Journal, 11, 195-298.

Csikszentmihalyi, M. (1975). Beyond boredom and anxiety. San Francisco: Jossey-Bass.

Deck, A.A. (1990). Auto-ethnography: Zora Neale Hurston, Noni Jabavu, and cross-disciplinary discourse. Black American Literature Forum, 24, 237-256. 
Denison, J., \& Rinehart, R. (2000). Introduction: Imagining sociological narratives. Sociology of Sport Journal, 17, 1-4

Durkheim, E. (1976). The elementary forms of religious life (2nd ed.). London: George Allen \& Unwin.

Eichberg, H. (1998). Body cultures: Essays on sport, space and identity (J. Bale \& C. Philo, Eds., with a contribution by S. Brownell). London: Routledge.

Fine, G.A. (1990). Organizational time: Temporal demands and the experience of work in restaurant kitchens. Social Forces, 69, 95-114.

Flaherty, M.G. (1999). A watched pot: How we experience time. New York: New York University Press.

Foucault, M. (1979). Discipline and punish: The birth of the prison. London: Penguin.

Frey, J.H. (1991). Social risk and the meaning of sport. Sociology of Sport Journal, 8, 136145.

Glaser, B., \& Strauss, A. (1967). The discovery of grounded theory. Chicago: Aldine.

Goffman, E. (1972). Encounters. Harmondsworth: Penguin.

Goodridge, J. (1999). Rhythm and timing of movement and performance. London: Jessica Kingsley.

Goodwin, C. (1995). Seeing in depth. Social Studies of Science, 25, 237-274.

Granskog, J. (2003). Just "Tri" and "Du" it: The variable impact of female involvement in the triathlon/duathlon sport culture. In A. Bolin \& J. Granskog (Eds.), Athletic intruders. Ethnographic research on women, culture, and exercise (pp. 27-52). New York: State University of New York Press.

Greenhalgh, S. (2001). Under the medical gaze: Facts and fictions of chronic pain. Berkeley: University of California Press.

Grisogono, V. (1988). Knee health: Problems, prevention and cure. London: John Murray.

Grisogono, V. (1989). Sports injuries: A self-help guide. London: John Murray.

Gurvitch, G. (1964). The spectrum of social time. Dordrecht: D. Reidel.

Harvey, J., \& Sparks, R. (1991). The politics of the body in the context of modernity. Quest, 61, 164-189.

Heil, J. (1993). Psychology of sport injury. Champaign, IL: Human Kinetics.

Howe, P.D. (2001). An ethnography of pain and injury in professional Rugby Union: The case of Pontypridd RFC. International Review for the Sociology of Sport, 36, 289303.

Kleinman, A.M.D. (1988). The illness narratives: Suffering, healing and the human condition. New York: Basic Books.

Krane, V., Greenleaf, C.A., \& Snow, J. (1997). Reaching for gold and the price of glory: A motivational case study of an élite gymnast. The Sport Psychologist, 11, 53-71.

Lawrence, J.H. (1994). Campus culture and faculty perceptions of time. New Directions for Institutional Research, 83, 25-38.

Leder, D. (1990). The absent body. Chicago: University of Chicago Press.

Lofland, J., \& Lofland, L.H. (1995). Analyzing social settings: A guide to qualitative observation and analysis (3rd ed.). Belmont, CA: Wadsworth.

Lowe, B. (1977). The beauty of sport: A cross-disciplinary enquiry. Englewood Cliffs, NJ: Prentice Hall.

Luhmann, N. (1982). The differentiation of society (S. Holmes \& C. Larmore, Trans.). New York: Columbia University Press.

Mauss, M. (1966). Sociologie et anthropologie. Paris: Presses Universitaires de France.

Mead, G.H. (1959/1932). The philosophy of the present (A.E. Murphy, Ed.). La Salle, IL: Open Court. 
Melucci, A. (1996). The playing self: Person and meaning in the planetary society. Cambridge: Cambridge University Press.

Messner, M.A. (1992). Power at play: Sports and the problem of masculinity. Boston: Beacon Press.

Métoudi, M. (1994). Sociology of sport and space. A productive bet. International Review for the Sociology of Sport, 29, 367-380.

Nixon, H.L. (1992). A social network analysis of influences on athletes to play with pain and injuries. Journal of Sport and Social Issues, 16, 127-135.

Ochs, E., \& Capps, L. (1996). Narrating the self. Annual Review of Anthropology, 25, 19-43.

Okley, J., \& Callaway, H. (1992). Anthropology and Autobiography. London: Routledge.

Reed-Danahay, D. (Ed.). (1997). Auto/Ethnography. Oxford: Berg.

Richardson, L. (1995). Narrative and sociology. In J. Van Maanen (Ed.), Representation in ethnography (pp. 198-221). London: Sage.

Robbins, J.M., \& Joseph, P. (1980). Commitment to running: Implications for family and work. Sociological Symposium, 30(spring), 87-108.

Rosenblum, B. (1990). I have begun the process of dying. In J. Spence \& P. Holland (Eds.), Family snaps: The meaning of domestic photography. London: Virago.

Roy, D. (1959-60). Banana time: Job satisfaction and informal interaction. Human Organization, 18, 158-168.

Sands, R.R. (1995). Instant acceleration: Living in the fast lane. The cultural identity of speed. Lanham, NY: University Press of America.

Sanjek, R. (Ed.). (1990). Fieldnotes: The makings of anthropology. Ithaca, NY: Cornell University Press.

Schutz, A (1932). The phenomenology of the social world. Evanston, IL: Northwestern University Press.

Schutz, A., \& Luckman, T. (1973). The structure of the life world (R.M. Zaner \& H.T. Engelhardt Jr., Trans.). London: Heinemann.

Segrave, J.O. (2000). Sport as escape. Journal of Sport \& Social Issues, 24, 61-77.

Seymour, W. (1998). Remaking the body: Rehabilitation and change. London: Routledge.

Shaffer, S.M. (1996). Grappling with injury: What motivates young athletes to wrestle with pain? Unpublished doctoral dissertation, University of Minnesota, Minneapolis.

Shore, B. (1994). Marginal play: Sport at the borderlands of time and space. International Review for the Sociology of Sport, 29, 349-366.

Smith, G. (2002). Racing against time? Aspects of the temporal organization of the runner's world. Symbolic Interaction, 25, 343-362.

Sorokin, P.A., \& Merton, R.K. (1937). Social time: A methodological and functional analysis. American Journal of Sociology, XLII, 615-629.

Sparkes, A.C. (1996). The fatal flaw: A narrative of the fragile body-self. Qualitative Inquiry, 2, 463-494.

Sparkes, A.C. (1998). Athletic identity: An Achilles' heel to the survival of the self. Qualitative Health Research, 8, 644-664.

Sparkes, A.C. (1999). Exploring body narratives. Sport, Education and Society, 4, 17-30.

Sparkes, A.C. (2000). Autoethnography and narratives of self: Reflections on criteria in action. Sociology of Sport Journal, 17, 21-43.

Sparkes, A.C., \& Silvennoinen, M. (Eds.). (1999). Talking bodies: Men's narratives of the body and sport. Jyväskylä, Finland: SoPhi.

Stanley, L. (1992). The auto/biographical I. Manchester: Manchester University Press.

Stebbins, R.A. (1982). Serious leisure. A conceptual statement. Pacific Sociological Review, 25, 251-272. 
Strathern, M. (1987). The limits of auto-anthropology. In A. Jackson (Ed.), Anthropology at home (pp. 16-37). London: Tavistock.

Stryker, S. (1987). Identity theory: Developments and extensions. In K. Yardley \& T. Honess (Eds.), Self and identity: Psychosocial perspectives (pp. 89-103). New York: John Wiley.

Taylor, J., \& Taylor, S. (1997). Psychological approaches to sports injury rehabilitation. Gaithersburg, MA: Aspen.

Thompson, E.P. (1967). Time, work-discipline and industrial capitalism. Past and Present, 38(December), 56-97.

Thrift, N. (1990). The making of a capitalist time consciousness. In J. Hassard (Ed.), The sociology of time (pp. 105-129). London: Macmillan.

Wacquant, L. (1995). Pugs at work: Bodily capital and bodily labour among professional boxers. Body and Society, 1, 65-93.

Walk, S. (1997). Peers in pain. Sociology of Sport Journal, 14, 22-56.

Wiese-Bjornstal, D.M., Smith, A.M., Shaffer, S.M., \& Morrey, M.M. (1998). An integrated model of response to sport injury: Psychological and sociological dynamics. Journal of Applied Sport Psychology, 10, 46-69.

Wulff, H. (1998). Ballet across borders: Career and culture in the world of dancers. Oxford: Berg.

Yakura, E.K. (2001). Billables: The valorization of time in consulting. American Behavioural Scientist, 44, 1076-1095.

Young, K., \& White, P. (1995). Sport, physical danger and injury: The experience of élite women athletes. Journal of Sport and Social Issues, 19, 45-61.

Young, K., White, P., \& McTeer, W. (1994). Body talk: Male athletes reflect on sport, injury and pain. Journal of Sport \& Social Issues, 11, 175-194.

Zeruvabel, E. (1979). Patterns of time in hospital life. Chicago: University of Chicago Press.

Zeruvabel, E. (1981). Hidden rhythms. Schedules and calendars in social life. Chicago: University of Chicago Press.

\section{Acknowledgments}

The author wishes to thank Dr. John Hockey, the editor, and the anonymous reviewers for their helpful comments on an earlier draft. 